\title{
summary
}

\section{CEREC shows high survival rate at 4 years}

Martin N, Jedynakiewicz NM. Performance of CEREC Ceramic inlays: a systematic review. Dental Mater 1999; 15:54-61

Objective To identify the clinical performance of intra-coronal CEREC restorations luted with an adhesive composite technique.

Data sources Computer databases, symposium proceedings and reference lists for 1986-1997.

Study selection Trials undertaken in controlled dental practice situation, or university environment, measuring the performance of CEREC as an intra-coronal restorative were included if a thorough and consistent placement and evaluation protocol was used. In cases of multiple reporting only the latest or most detailed reported was included.

Results Fifteen of the 29 identified studies were included in the review. Fracture of the ceramic was the primary mode of failure. The most common short-term complication was thermal hypersensitivity.

\begin{tabular}{lcccc}
\hline $\begin{array}{l}\text { Included } \\
\text { studies }\end{array}$ & $\begin{array}{c}\text { Study period } \\
\text { (Range) }\end{array}$ & $\begin{array}{c}\text { Total number } \\
\text { of inlays }\end{array}$ & $\begin{array}{c}\text { Number of } \\
\text { inlays per study } \\
\text { (Range) }\end{array}$ & $\begin{array}{c}\text { \% Fractured } \\
\text { inlays } \\
\text { (Range) }\end{array}$ \\
\hline 15 & $\begin{array}{c}20 \text { months } \\
-10 \text { yrs }\end{array}$ & 2862 & $8-1011$ & $0-25$ \\
\hline
\end{tabular}

No meta-analysis was performed but the survival rate was estimated at $97.4 \%$ at 4.2 years.

Conclusion Machinable ceramics as used by CEREC system provide a useful restoration with a high success rate.

Address for reprints: N Martin, Department of Clinical Dental Sciences, The University of Liverpool, Liverpool L69 3BX, UK.

E-mail: nmartin@liverpool.ac.uk

\section{Commentary}

A paper with a title that includes the term 'systematic review' creates certain anticipation. A systematic review as defined by e.g. the Cochrane collaboration involves a rigorous process of identifying and selecting studies after an appraisal of various study design qualities. Unfortunately, this is not the case in this paper, as several clinical studies are lacking, mainly from German dental journals and there is a lack of description of the appraisal of the studies' external and internal validity.

The clinical studies that were not included, as well as subsequent papers that have recently been published ${ }^{1,2}$ show fairly similar results as presented in this review. There is thus little reason to presume that the data presented are selective, which show relatively good clinical performance of CEREC-fabricated ceramic inlays.
A large share of the 15 studies included in the review is from the proceedings of two industry-sponsored symposia on computer restorations. It is questionable that these studies can be appraised on the same level as papers published in peer-reviewed journals. The authors suggest that the study setting, i.e. university or private practice, have little influence on the clinical performance. However, the data from the five studies in general practice are proceedings papers, while the data from the university settings are mainly from journal articles.

It is commendable that the authors suggest that more structured studies than at present are required to analyse problems that have been identified with ceramic inlays.

Finally, it must be emphasised that when considering the merit of restoring teeth it is of minor interest what happens to the restoration relative to what happens to the remaining tooth tissues over time. A minimal intervention strategy should be regarded as the best modus operandi for avoiding adverse effects ${ }^{3}$. Unfortunately, this may often not be compatible with the use of brittle materials such as ceramics.

1. Molin M, Karlsson SL. A randomized 5-year clinical evaluation of 3 ceramic inlay systems. Int J Prosthodont 2000; 13:194200.

2. Pallesen U, van Dijken JW. An 8-year evaluation of sintered ceramic and glass ceramic inlays processed by the Cerec CAD/CAM system. Eur J Oral Sci 2000;108:239-246.

3. Mount GJ, Hume WR. Preservation and restoration of tooth structure. London: Mosby International Ltd., 1998.

Asbjørn Jokstad University of Oslo, Norway 